\title{
REABILITAÇÃO DE PAVIMENTOS RÍGIDOS INCORPORADOS AO TABULEIRO DE OBRAS DE ARTES ESPECIAIS
}

\section{REHABILITATION OF RIGIDS PAVEMENTS INCORPORATED TO THE TRAY OF SPECIAL ARTS WORKS}

\author{
Fábio Benetti Sales Camargo'; Erickson Lima Arving². \\ Universidade do Oeste Paulista - UNOESTE, 'Discente da Pós graduação lato sensu de \\ Infraestrutura Rodoviária; ${ }^{2}$ Docente de Engenharia Civil, Presidente Prudente, SP. \\ E-mail: fabiobenettisc@yahoo.com.br ${ }^{1}$;
}

RESUMO - O pavimento rígido de concreto incorporado à laje do tabuleiro é um pavimento de concreto Portland executado separadamente da laje, porém com posterior incorporação a essa laje por meio de grampos. No processo de recuperação desse tipo de pavimento, é necessária a execução de avaliações estruturais do pavimento, para serem definidos quais serviços devem ser executados, os locais de execução, os tempos aproximados de obra e o grau de necessidade desses serviços. O trabalho em questão teve como objetivo descrever todo esse processo de reabilitação de pavimentos rígidos de concreto em cimento Portland, pegando como exemplo uma ponte de tráfego intenso e sem possibilidade de interrupção total do tráfego.

Palavras-chave: pavimento rígido; incorporação; reabilitação.

Recebido em: $11 / 12 / 2017$

Revisado em: 05/02/2018

Aprovado em: 27/02/2018
ABSTRACT - The rigid concrete floor incorporated in the slab of the board is a Portland concrete pavement executed separately from the slab, but later incorporating to this slab by means of staples. In the process of recovery of this type of pavement, it is necessary to perform structural evaluations of the pavement, to be defined which services are to be executed, the execution sites, the approximate times of work and the degree of necessity of these services. The objective of this work was to describe the whole process of rehabilitation of concrete pavements in Portland cement, taking as an example a bridge of intense traffic and without possibility of total interruption of traffic.

Keywords: rigid pavement; incorporation; rehabilitation. 


\section{INTRODUÇÃO}

De acordo com Mesquita (2001), o pavimento rígido como alternativa de pavimentação em estradas é uma solução já utilizada a mais de um século, pois é sabido que o mesmo foi utilizado no ano de 1865, na cidade de Invernes, Escócia.

Senço (apud SILVA; CARNEIRO, 2014, p. 15), diz que foram com os ingleses que se deu o início do uso dos pavimentos rígidos no ano de 1865, sendo que em 1891 o calçadão para pedestres executado na cidade de Bellefontaine, Ohio foi o primeiro pavimento rígido construído nos Estados Unidos.

Não só nos Estados Unidos, mas também na Alemanha, o pavimento de concreto passou a ser o preferido para as autoestradas, sendo que no final de 1950, os Estados Unidos tinham cerca de $89 \%$ das vias urbanas e $79 \%$ das vias rurais pavimentadas em concreto e a Alemanha, antes da 2a Guerra Mundial tinha cerca de $92 \%$ de suas autoestradas com esse tipo de pavimento (SILVA; CARNEIRO, 2014).

As primeiras estradas de concreto construídas na América Latina foram executadas na Argentina e no México entre as décadas de 1920 e 1930 (MESQUITA, 2001) e de acordo com Silva e Carneiro, 2014, no ano de 1926 foi executada a primeira obra de pavimento de concreto no Brasil, mais precisamente na ligação entre São Paulo e Cubatão, também conhecida como Caminho do Mar.

De acordo com Mesquita (2001, p. 2), sabemos que:

No Brasil, como de modo geral na América Latina, a construção de pavimentos de concreto, não tive um desenvolvimento

harmônico; do entusiasmo inicial dos anos 19201950, se seguiu um estancamento relativo em 1960-1990, devido à competência agressiva dos pavimentos asfálticos.

\section{OBJETIVOS}

Objetivo Geral

O presente trabalho tem por objetivo realizar um estudo sobre a reabilitação de pavimentos rígidos em pontes incorporados à laje do tabuleiro, utilizando um exemplo de aplicação para análise e compreensão do método.

Objetivos Específicos

- Descrever o processo de incorporação e reabilitação de pavimentos rígidos no tabuleiro de obras de arte especiais.

- Examinar e verificar as particularidades e o método construtivo.

\section{PAVIMENTO DE CONCRETO SOBRE PONTES INCORPORADO AO TABULEIRO}

A norma do Departamento de Estrada e Rodagem do Estado de São Paulo - DER/SP - ET-DE-P00/047 (2007, p. 3), diz que:

O pavimento de concreto de cimento Portland incorporado à laje do tabuleiro, comumente denominado como pavimento incorporado às obras de arte especiais, é o pavimento de concreto executado separadamente da laje do tabuleiro, mas aderido a esta por meio de grampos devidamente posicionados na laje.

O manual de pavimentos rígidos do DNIT (2005) diz que quando o pavimento rígido é executado em tabuleiros de pontes e viadutos, o mesmo é chamado de sobre laje, sendo que as características dimensionais deste pavimento constam na norma DNERES-OA-36/96 - Sobre laje, e que a espessura deverá ser de no mínimo $8 \mathrm{~cm}$, a sobre laje deverá estar perfeitamente aderida ao tabuleiro, a colocação da tela de armação deverá estar à meia espessura da sobre laje, com distância $5 \mathrm{~cm}$ de qualquer bordo e na hipótese de inserção de duas telas, a inferior deverá ser fixada por meio de barras de aço cravadas na laje do tabuleiro.

Segundo norma do Departamento de Estrada e Rodagem do Estado de São Paulo - 
DER/SP - ET-DE-P00/047 (2007) telas soldadas para combate da fissuração, devem ser empregadas durante a execução do pavimento e o concreto a ser utilizado, deve apresentar a resistência à tração na flexão definida no projeto.

Novamente, norma do Departamento de Estrada e Rodagem do Estado de São Paulo - DER/SP - ET-DE-P00/047 (2007, p. 3), explica que:

Os grampos podem ser executados com aço CA-50 com diâmetro $8,0 \mathrm{~mm}$ ou CA-25 com diâmetro de 10,0 mm. Quando houver necessidade de liberação ao tráfego entre a concretagem da laje e o pavimento, os grampos devem ser executados em aço CA-25, com disposição definida em projeto. A tela eletro-soldada deve ser de malha quadrada em aço CA-60 com a seção definida no projeto, podendo eventualmente ser utilizadas armaduras adicionais, conforme definidas em projeto. $O$ aço utilizado nos grampos deve obedecer à norma NBR 7480 e as telas soldadas empregadas no combate à fissuração devem atender à norma NBR 7481.

\section{REABILITAÇÃO DE PAVIMENTOS RÍGIDOS EM PONTES}

"A reabilitação de pavimentos rígidos sobre obra de arte desta especificação, refere-se aos procedimentos necessários para a condição de troca total da placa e recomposição com concreto de cimento Portland, solidarizando a laje do tabuleiro da OAE por meio de grampos" (DER/SP - ET-DEP00/046, 2007).

Muitas vezes, a necessidade da reabilitação de pavimentos rígidos, dá-se pela quebra da placa de concreto ocasionada pela fadiga do material.

Cervo (apud SILVA; CARNEIRO, 2014, p. 18), diz que a fadiga é o resultado de um processo de degradação progressiva na microestrutura do material o qual está sujeito às deformações ou as tensões de magnitudes inferiores à deformação ou à tensão de ruptura estática.

O manual de pavimentos rígidos do DNIT (2005), diz que "A reabilitação dos pavimentos rígidos deve ser feita após uma criteriosa avaliação das suas condições atuais, especialmente do seu ICP".

Segundo a norma DNIT 062/2004 PRO (2004), o índice de condição do pavimento (ICP), é a medida da condição estrutural do pavimento que fornece informações para a verificação da rodovia colaborando para diretrizes de políticas de manutenção, prevenção e recuperação de pavimentos.

Ainda de acordo com a norma DNIT 062/2004 - PRO (2004) é necessário seguir cinco fases para executar uma boa avaliação objetiva das condições estruturais do pavimento. São elas:

1. Análise dos dados obtidos na inspeção;

2. Cálculo dos índices de condição do pavimento;

3. Atribuição de conceitos;

4. Análise do cadastro documental e;

5. Emissão do laudo.

\section{REABILITAÇÃO DE PAVIMENTOS - MÉTODO EXECUTIVO}

Segundo a norma do Departamento de Estrada e Rodagem do Estado de São Paulo - DER/SP - ET-DE-P00/046 (2007, p. 5):

Os serviços reabilitação do pavimento rígido consistem na retirada através de demolição cuidadosa do pavimento contido pela área delimitada pelas juntas longitudinais e transversais e por pelo menos uma placa, preparo da superfície com limpeza e retirada de material solto; execução de grampos; posicionamento da tela eletro-soldada; 
concretagem; acabamento antiderrapante e cura.

A norma do Departamento de Estrada e Rodagem do Estado de São Paulo - DER/SP ET-DE-P00/046 (2007), também descreve o passo a passo dos serviços. São eles:

1. Demolição do pavimento degradado;

2. Preparo da superfície e retirada de material solto;

3. Execução dos grampos;

4. Concretagem;

5. Acabamento;

6. Cura e;

7. Abertura ao tráfego.

Durante a execução de todo o processo executivo da reabilitação de pavimentos rígidos, também são exigidos pela norma do Departamento de Estrada e Rodagem do Estado de São Paulo - DER/SP ET-DE-P00/046 (2007), três tipos de controles: os controles de materiais, os controles de execução e os controles ambientais. Nos procedimentos dos controles de materiais, devem ser executados ensaios referentes ao adesivo epoxídico utilizados para a fixação dos grampos e os ensaios referentes ao concreto utilizado no pavimento, nos controle de execução, devem ser realizadas inspeções visuais para verificação das condições de limpeza e aplicação dos materiais, além das condições de acabamento da superfície do pavimento e no controle ambiental, devem ser implantados na obra, uma série de procedimentos como, por exemplo, a implantação de sinalização de alerta e segurança, a proibição do tráfego de equipamentos fora do local da obra para evitar interferências desnecessárias a vegetação e drenagem natural, obrigatoriedade de uso de EPI's, entre outros.

\section{REABILITAÇÃO DO PAVIMENTO DA PONTE MAURÍCIO JOPPERT}

Na obra da recuperação do pavimento rígido da ponte Maurício Joppert, hoje conhecida como Hélio Serejo, que é uma das principais ligações entre os estados de Mato Grosso do Sul e São Paulo, o processo executivo foi semelhante ao descrito anteriormente, sendo divididos em várias etapas. São elas:

\subsection{Sinalização da obra e mobilização do sistema PARE-SIGA}

Devido à importância da ponte no contexto nacional, pois a mesma está em uma das rotas de escoamento de produtos agrícolas dos estados produtores da região centro-oeste do país rumo aos portos das regiões sudeste-sul e também devido à sua importância no contexto regional, pois é a única ligação entre a cidade polo de Presidente Prudente/SP, onde existem hospitais de referência, universidades, indústrias, etc. e grande parte da região sudoeste do estado do Mato Grosso do Sul, o DNIT (Departamento Nacional de Infraestrutura de Transportes), órgão responsável pela fiscalização das obras, optou por não fazer a interdição total da ponte para não prejudicar os interesses governamentais em níveis regionais e nacionais, e com isso foi implantado o sistema PARE-SIGA 24 horas, conforme as figuras 01 e 02.

Figura 01. Detalhe do sistema PARE\&SIGA do lado do MS.

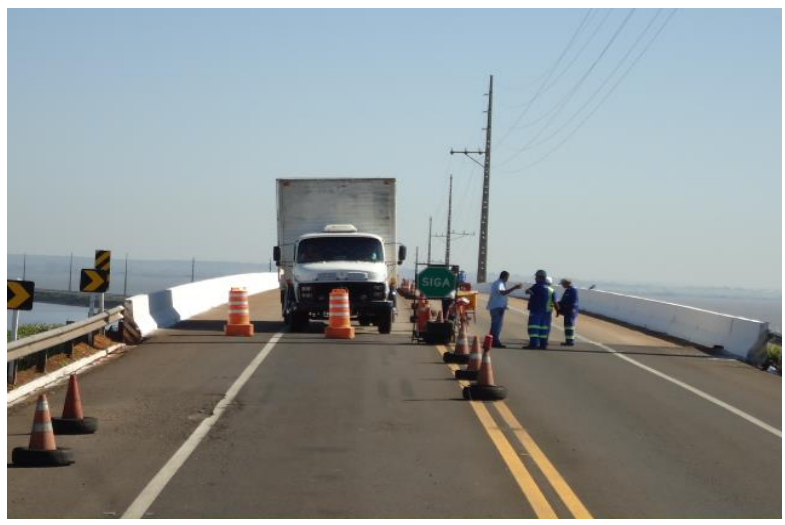

Fonte: O Autor (2012). 
Figura 02. Vista geral do sistema PARE\&SIGA do lado do MS. (TEXTO NÃO PRECISA ESTAR EM NEGRITO)

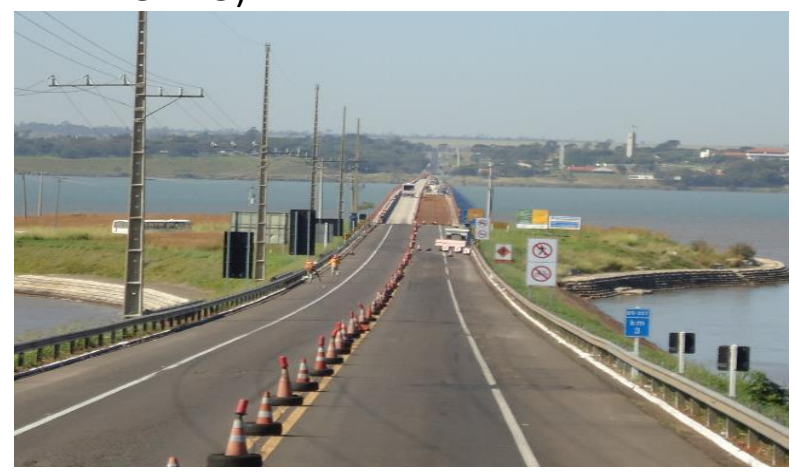

Fonte: O Autor (2012).

Além de solicitar a implantação de toda a sinalização de obras, o DNIT também solicitou a empresa responsável pela execução das obras, que o sistema PARE\&SIGA fosse implantado logo de imediato, sendo que as obras foram concentradas em um dos lados da ponte, tendo o outro lado liberado para tráfego com o auxílio de carro guia para o controle de velocidade máxima de $30 \mathrm{~km} / \mathrm{h}$ (figura 03), para dar uma maior segurança aos usuários que por ali trafegavam, às pessoas que ali trabalhavam e também para que houvesse o controle de frenagens e das vibrações do tráfego para que os mesmos não prejudicassem as concretagens do pavimento rígido de concreto. Após o término do primeiro lado em obras, o sistema PARE\&SIGA, foi deslocado para o lado já finalizado, para que os serviços fossem executados da mesma forma.
Figura 03. Carro guia para controle de velocidade do Sistema PARE\&SIGA em funcionamento.

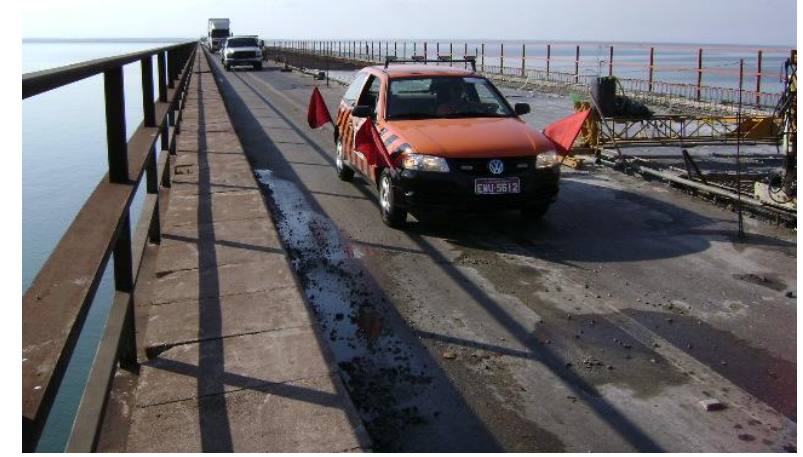

Fonte: O Autor (2012).

\subsection{Demolição do pavimento antigo}

O pavimento da ponte ainda era o mesmo desde a execução da obra entre os anos de 1959 e 1965 e o mesmo encontravase com nítidos sinais de fadiga, onde havia inúmeras trincas, material solto $e$ inexistência das juntas de dilatação, conforme figuras 04 e 05.

Figura 04. Piso antigo.

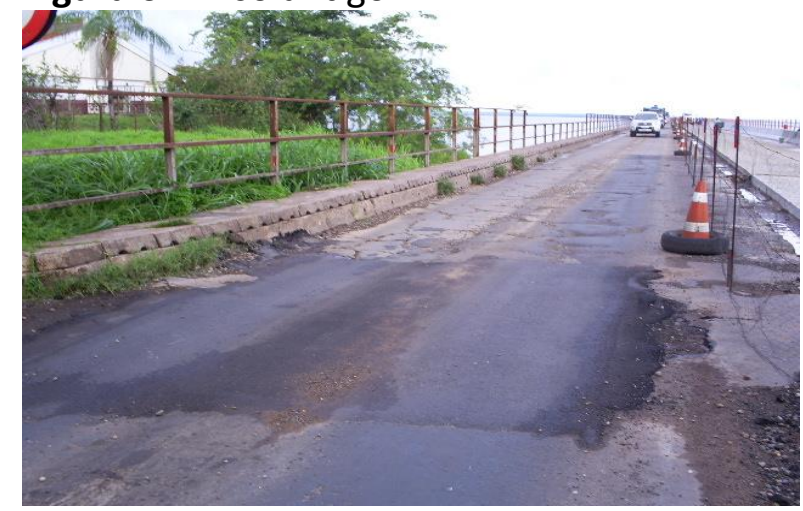

Fonte: O Autor (2012).

Figura 05. Piso antigo trincado.

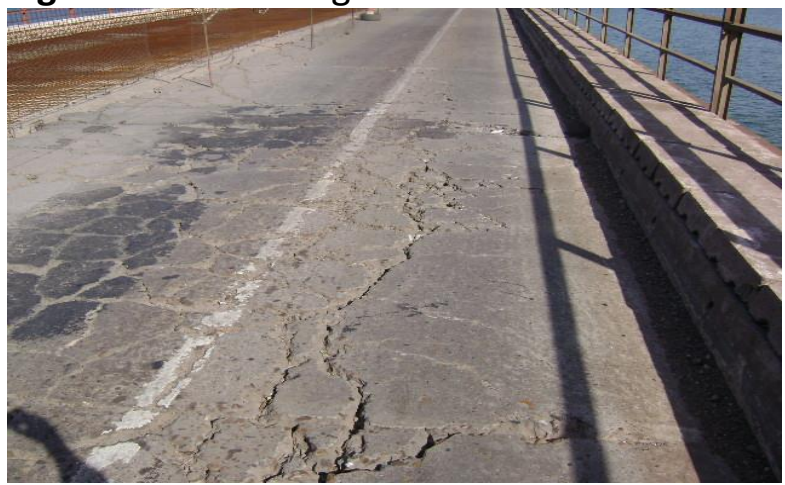

Fonte: O Autor (2012). 
Devido à grande quantidade de material a ser retirado da ponte e da espessura média do pavimento ser significativa, não foi possível fazer a demolição manual, sendo necessária a utilização de máquinas pesadas para execução da demolição e retirada dos materiais do local da obra. Todo esse material proveniente da demolição do pavimento de concreto antigo, foi depositado em um bota-fora licenciado pelo município de Presidente Epitácio/SP e disponibilizado como bota-fora, pois o município tinha interesse em usar o material, já que o mesmo é um material nobre e sem perigo de contaminação ao meio ambiente.

\subsection{Retirada do material fino e fresagem da superfície do tabuleiro}

A finalização da retirada do material fino proveniente da demolição do pavimento de concreto antigo da superfície do topo da laje do tabuleiro foi executada com o auxílio de vassouras e jato de ar. Finalizada essa limpeza fina, foi executado a fresagem do topo da superfície da laje com o auxílio de máquinas fresadoras, para que o topo da laje ficasse com ranhuras e desta forma, melhorasse a aderência entre a laje e o futuro pavimento de concreto (figura 06).

Figura 06. Topo da laje do tabuleiro fresado.

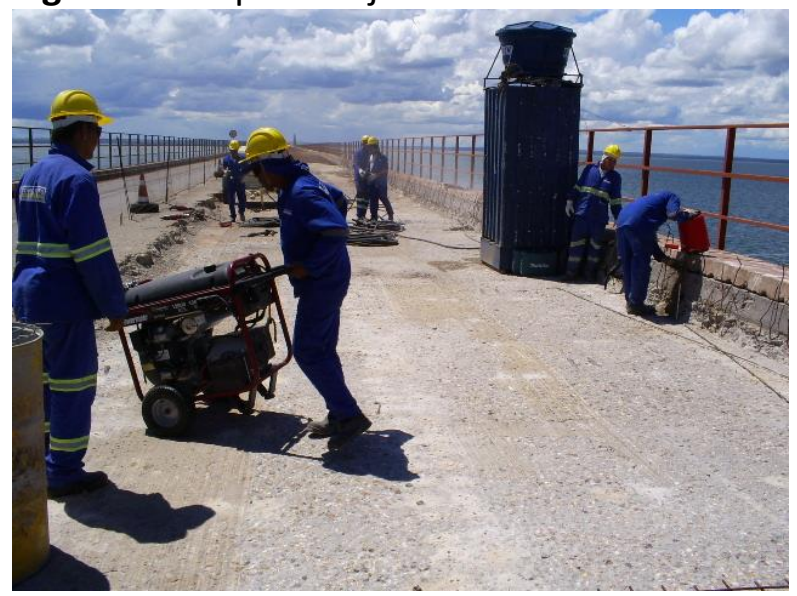

Fonte: O Autor (2012).

\subsection{Marcações para execução dos grampos, telas e concretagem final.}

Com o topo da laje do tabuleiro limpo e fresado, foram executadas as marcações das cotas finais de concretagem, tanto de eixo quanto de bordo. Essas marcações foram feitas por topógrafos contratados pela empresa responsável pelas obras, sempre respeitando as inclinações de projeto do pavimento, pois essas marcações também seriam referências para a execução da altura final dos grampos e telas, já que as mesmas deveriam ter um recobrimento mínimo de 4 $\mathrm{cm}$ com o pavimento acabado.

\subsection{Execução dos grampos e telas}

Após as marcações topográficas executadas, os serviços de execução dos grampos eram iniciados. Primeiramente, foi executada uma frente de serviço com o pessoal responsável por executar, com o auxílio de furadeiras elétricas, os furos nos locais e profundidades estabelecidos em projeto, como mostra a figura 07.

Figura 07. Execução dos grampos de aço.

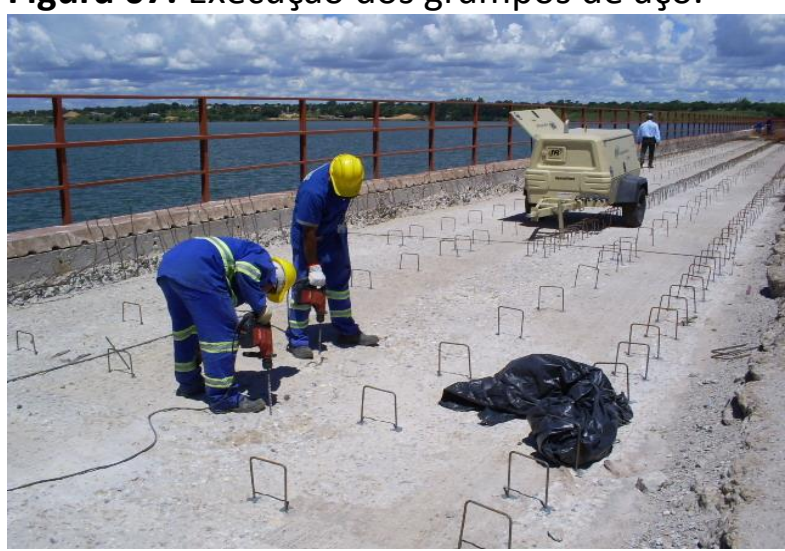

Fonte: O Autor (2012)

Conforme as frentes de serviço de execução de furos fossem executadas, outra equipe era responsável por fazer o preenchimento dos furos com cola epóxídica e a fixação dos grampos em aço CA-50, que já vinham cortados e dobrados do canteiro de obras, na altura indicada no projeto.

Após a fixação dos grampos na laje do tabuleiro, eram executados a colocação e fixagem das telas nos grampos engastados além da conferência da altura da tela a ser amarrada, com relação à altura mínima de cobrimento de $4 \mathrm{~cm}$ para a concretagem final (figura 08). 
Figura 08. Execução da fixação das telas de aço.

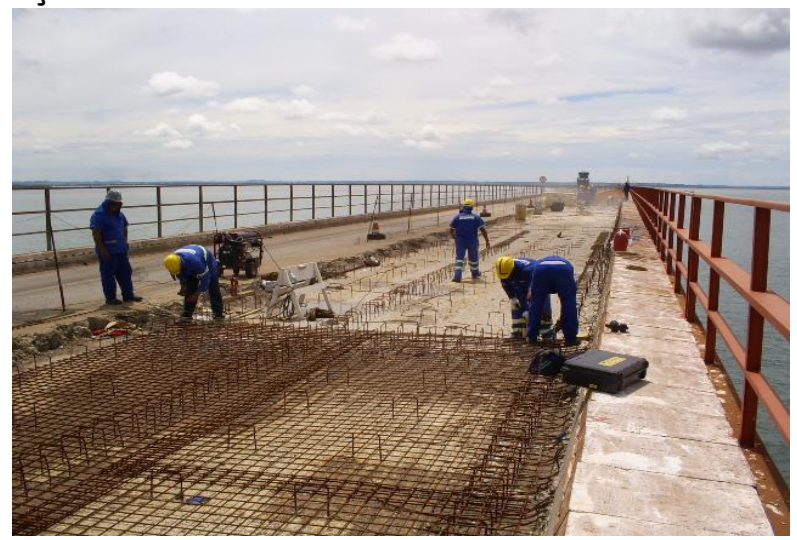

Fonte: O Autor (2012).

\subsection{Concretagem noturnas}

Simultaneamente, às frentes de serviço descritas anteriormente, todos os equipamentos necessários para a execução da concretagem final eram montados por outra equipe. Nessa etapa, também era necessário o auxílio de topógrafos para que não houvesse erros no nivelamento do pavimento final em concreto.

Longitudinalmente aos grampos e telas, eram montados os trilhos para o equipamento de nivelamento mecânico.

As concretagens eram feitas com o uso de caminhão betoneira, interditando a pista usada para o tráfego (figura 09) durante a concretagem, além do auxílio de vibradores (figura 10).

Figura 09. Caminhão betoneira.

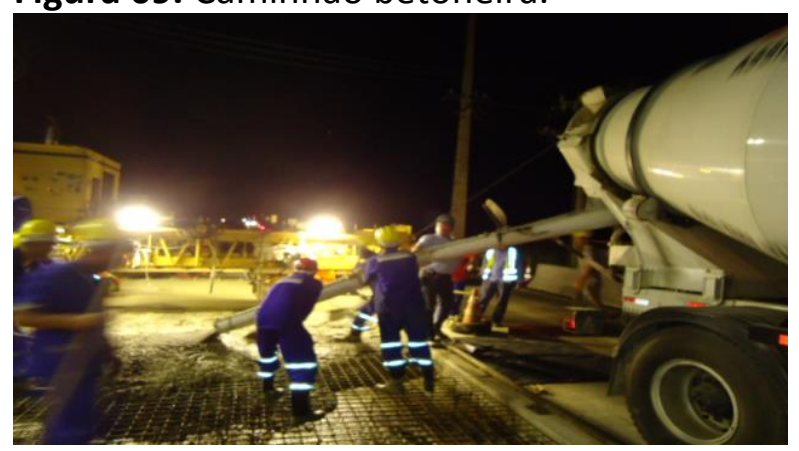

Fonte: O Autor (2012).
Figura 10. Uso de vibradores na concretagem.

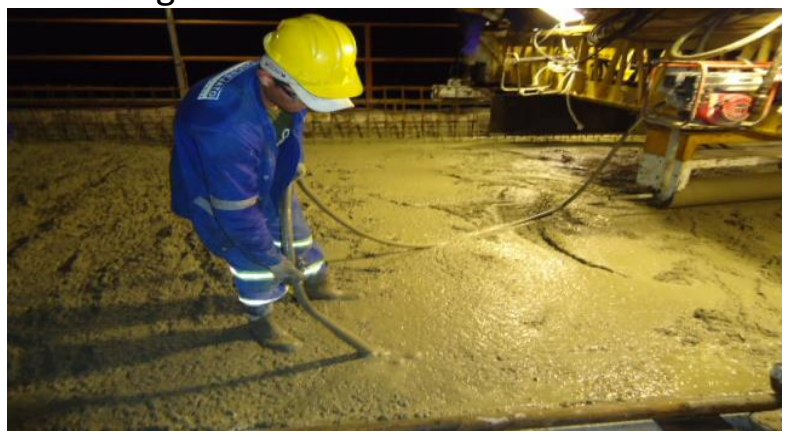

Fonte: O Autor (2012).

Devido o pavimento ser sobre a laje da ponte, o pano concretado era limitado pela distância entre as juntas de dilatação de projeto que eram variadas dependendo das características estruturais dos vãos da ponte.

Também foram montadas barreiras de tapumes em Madeirit para contenção dos fortes ventos laterais à ponte, pois os mesmos causariam fissuras e trincas durante o processo de cura, conforme mostra a figura 11.

Figura 11. Tapumes para contenção de vento lateral.

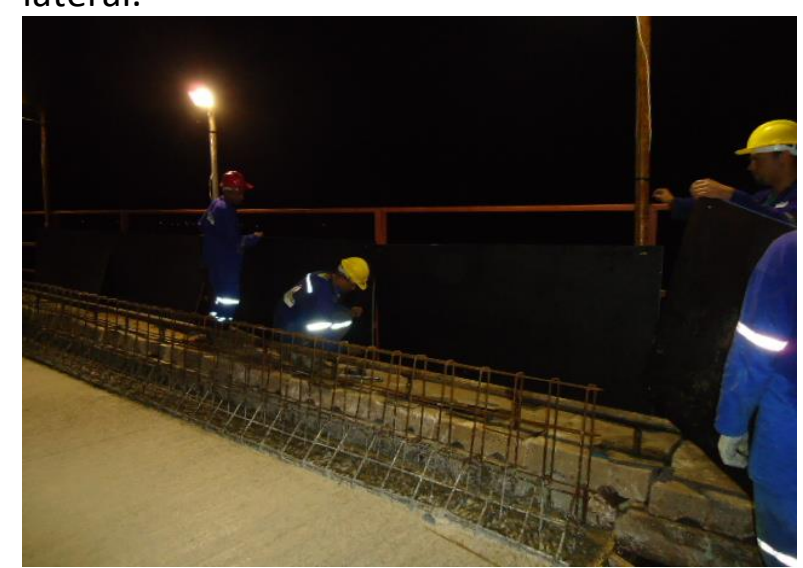

Fonte: O Autor (2012).

\subsection{Acabamento e cura}

Simultaneamente à execução da concretagem, nivelamento mecânico e acabamento manual do pano (figura 12), além do longo comprimento da área a ser concretada, eram executados os processos das ranhuras transversais ao tráfego (figura 13) e da execução da cura química (figura 14). 
Figura 12. Nivelamento mecânico do pavimento ao fundo com acabamento manual.

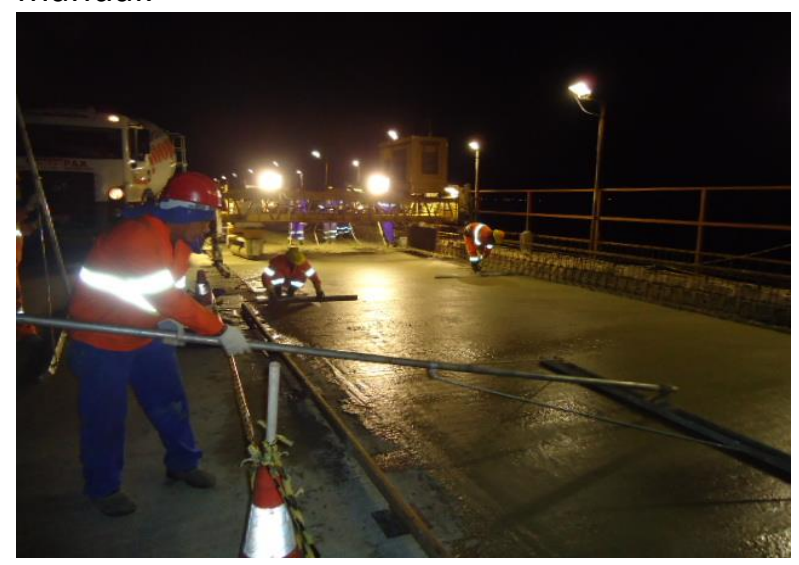

Fonte: O Autor (2012).

Figura 13. Execução de ranhuras transversais ao tráfego.

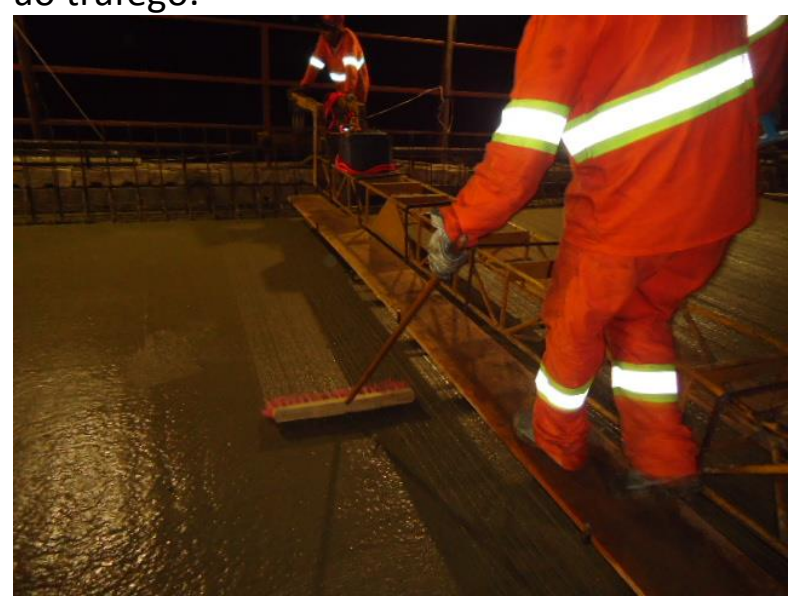

Fonte: O Autor (2012).

Figura 14. Cura química do pavimento rígido de concreto.

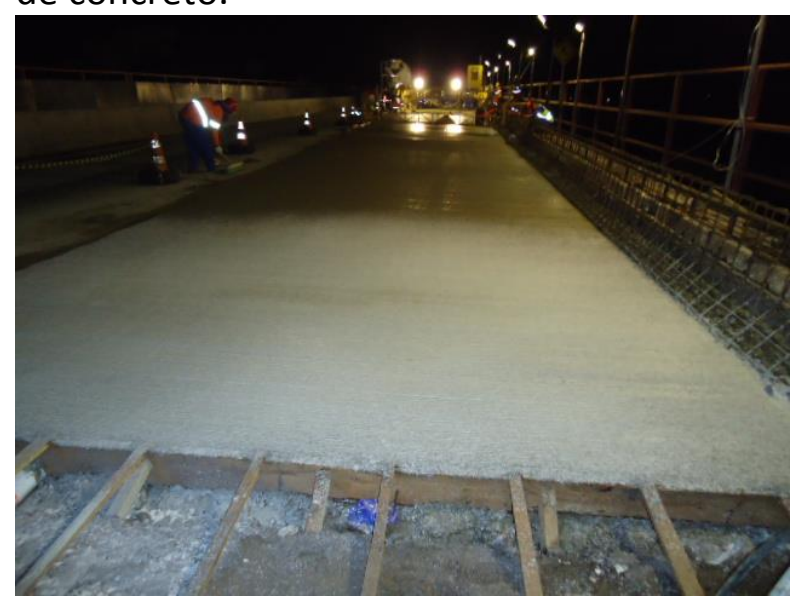

Fonte: O Autor (2012).

Esse processo era necessário de modo que $o$ concreto não perdesse suas características e não sofresse o processo de fissuração.

Na manhã seguinte, eram executadas as serragens das juntas de dilatação intermediárias (figura 15), além do início do processo de cura úmida (figuras 16 e 17), utilizando-se mantas geotêxtis, canos de PVC para liberação de água no sistema de gotejamento e bombas de sucção para bombear a água do próprio rio Paraná, que era de ótima qualidade, e dessa forma deixar as mantas geotêxtis $24 \mathrm{~h}$ úmidas durante 15 dias sem interrupção.

Figura 15. Serragem das juntas de dilatação intermediárias.

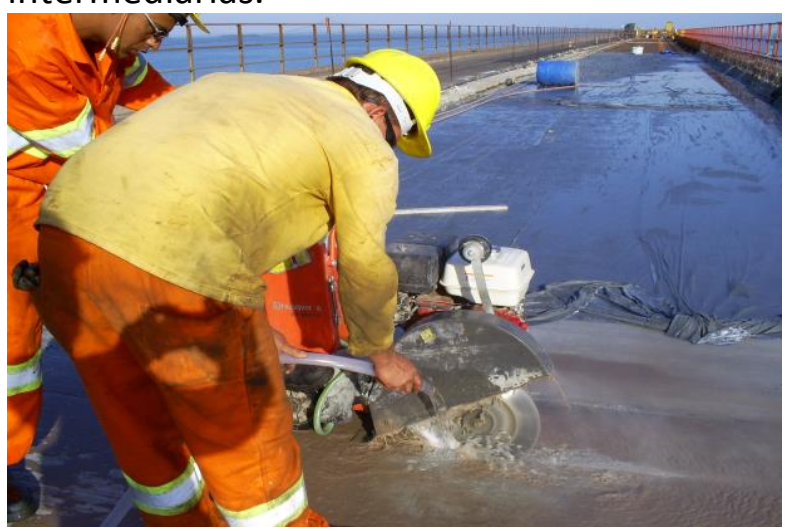

Fonte: O Autor (2012).

Figura 16. Execução da cura úmida pavimento de concreto com manta geotêxtil umidecida.

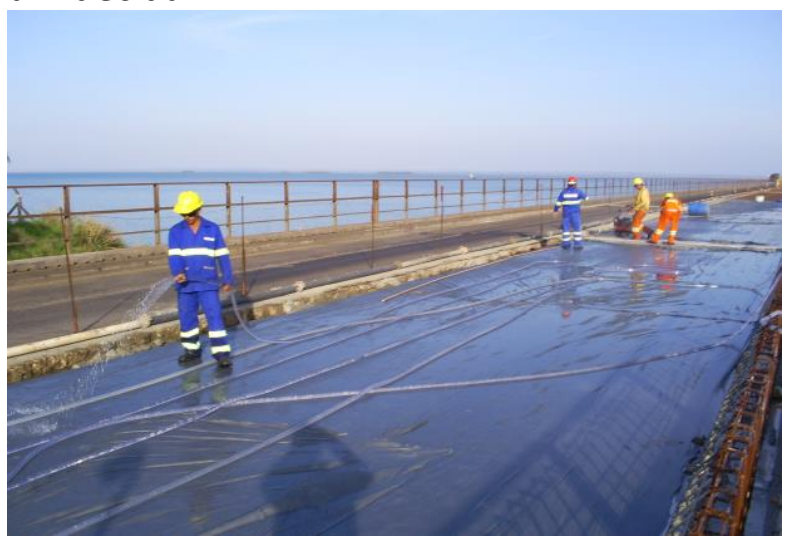

Fonte: O Autor (2012). 
Figura 17. Execução da cura úmida do pavimento de concreto com manta geotêxtil.

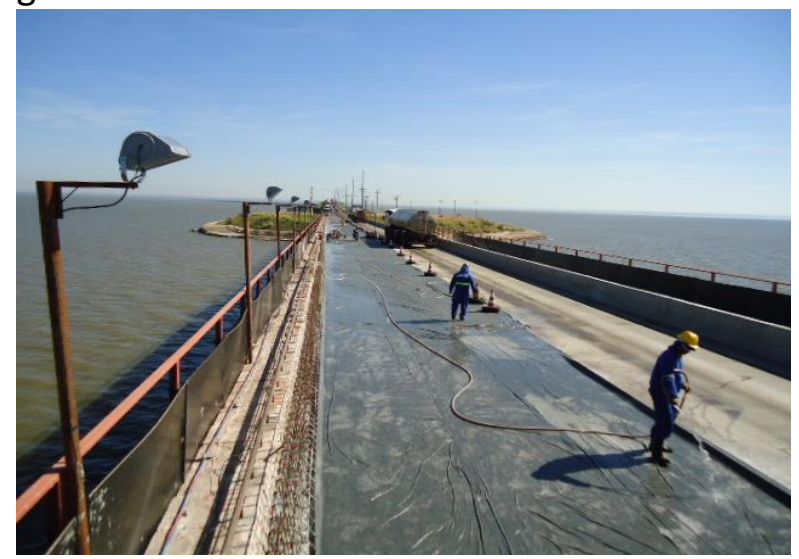

Fonte: O Autor (2012).

6.6. Execução dos lábios poliméricos e juntas de dilatação

Para posterior execução dos lábios poliméricos em argamassa epoxídica, eram moldadas fôrmas em isopor e Madeirit (figura 18). Os lábios seriam executados após a finalização dos 15 dias da cura úmida, mostrado pelas figuras 19 e 20 .

Figura 18. Fôrmas de isopor e Madeirit para posterior execução dos lábios poliméricos.

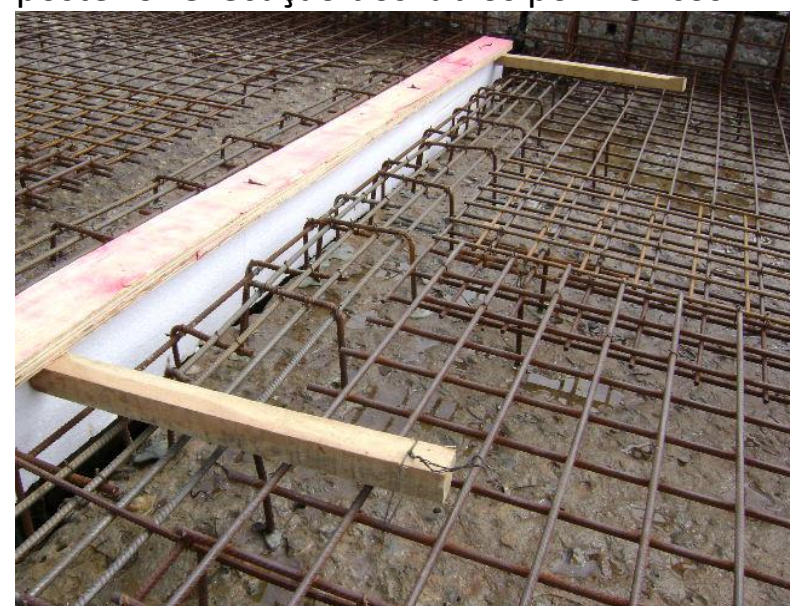

Fonte: O Autor (2012).
Figura 19. Execução acabamento final de um dos lábios poliméricos.

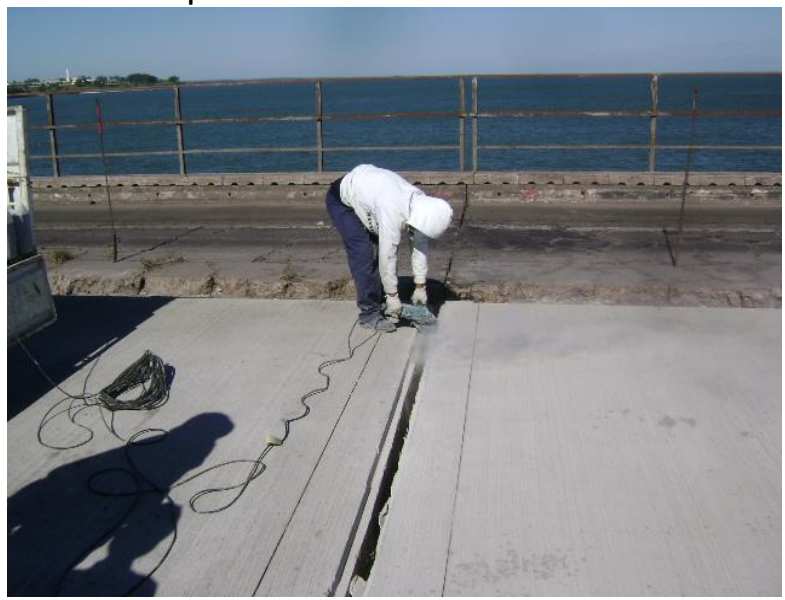

Fonte: O Autor (2012).

Figura 20. Execução de um dos lábios poliméricos.

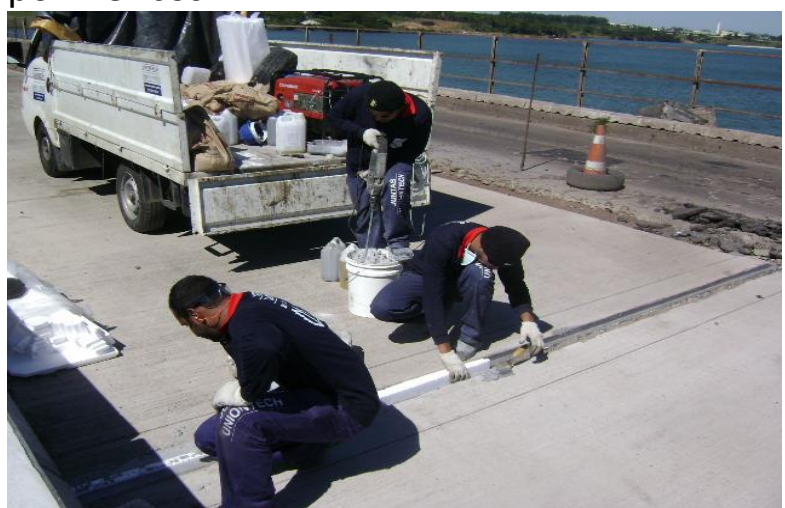

Fonte: O Autor (2012).

Após alguns dias da finalização da execução dos lábios poliméricos, eram executados os serviços de fixação das juntas de dilatação de borracha (figuras 21 e 22).

Figura 21. Execução das juntas de dilatação de borracha entre um dos pilares da ponte, com os lábios poliméricos já executados.

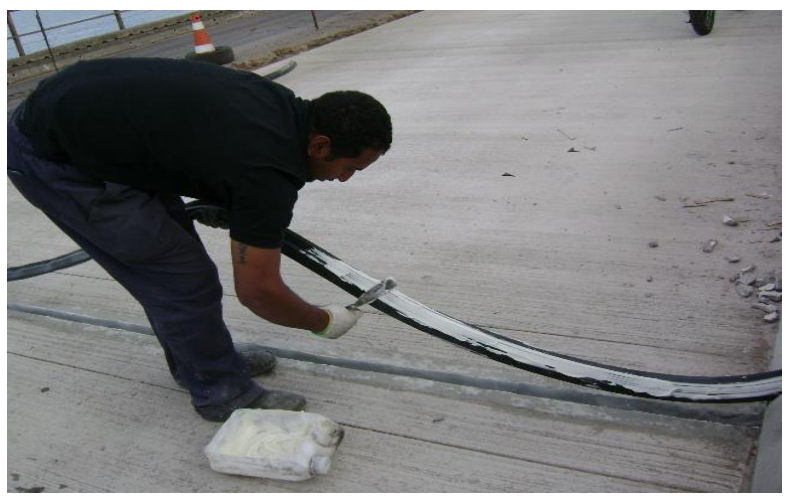

Fonte: O Autor (2012). 
Figura 22. Detalhe da execução das juntas de dilatação de borracha entre um dos pilares da ponte, com os lábios poliméricos já executados.

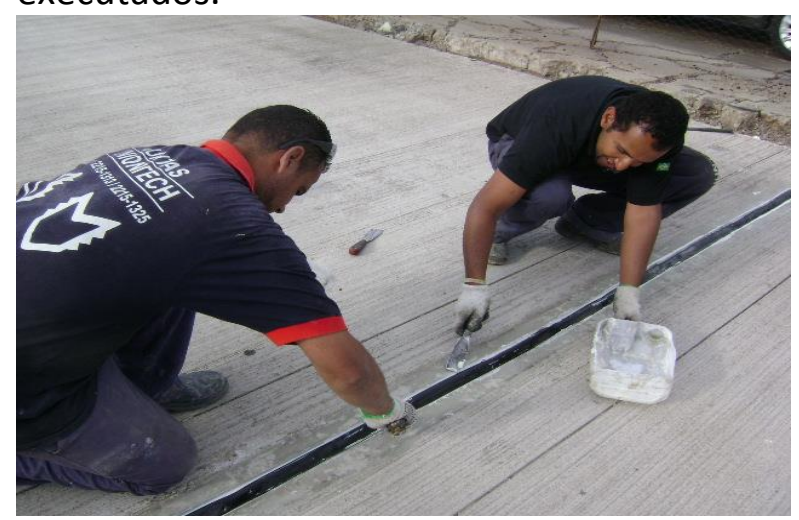

Fonte: O Autor (2012).

6.7. Execução das barreiras New Jersey, implantação dos guarda-corpos e outros serviços complementares.

A montagem das ferragens das barreiras de proteção, também conhecidas como "Barreiras New Jersey", mostrada nas figuras 23 e 24, era executada juntamente com a montagem das telas, pois as mesmas foram engastadas no pavimento de concreto. Somente a sua concretagem é que seria feita posteriormente com o auxílio de fôrmas metálicas (figura 25).

Figura 23. Montagem das ferragens das barreiras "New Jersey".

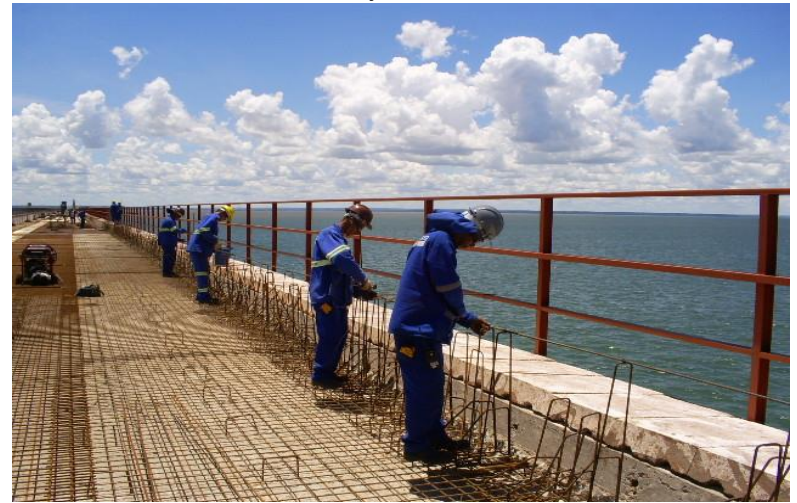

Fonte: O Autor (2012).
Figura 24. Ferragem das barreiras "New Jersey" concluídas.

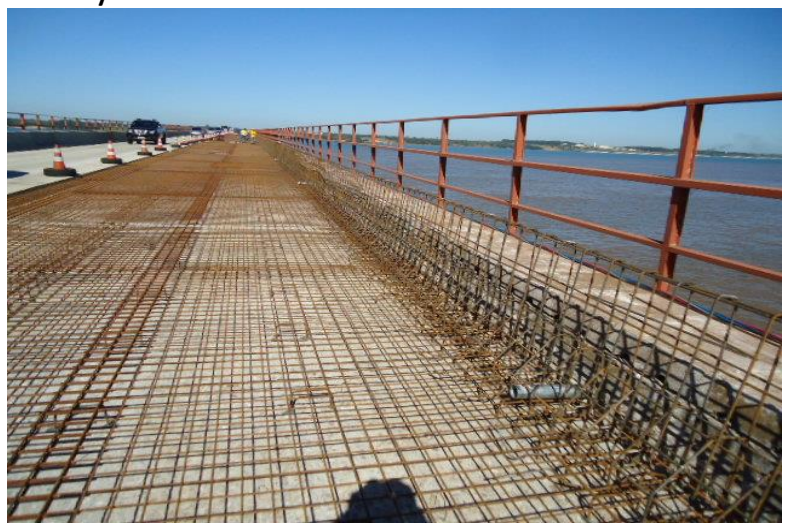

Fonte: O Autor (2012).

Figura 25. Montagem das fôrmas metálicas para execução da concretagem das barreiras "New Jersey".

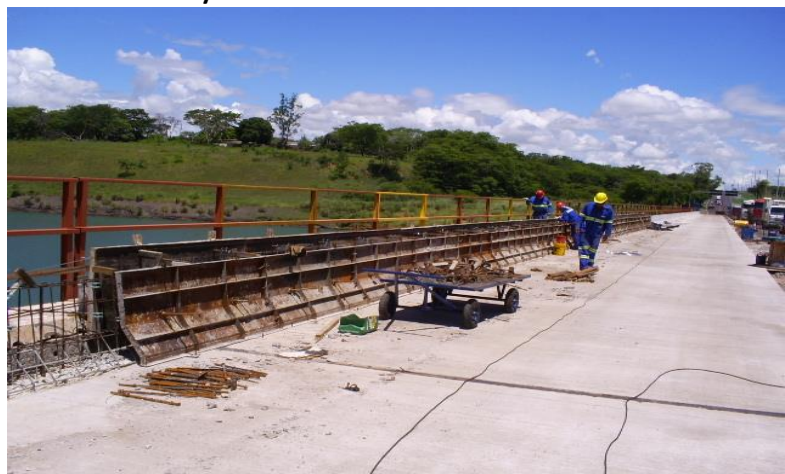

Fonte: O Autor (2012).

No topo da barreira de concreto, também foram implantados gradis de aço para auxiliar na proteção lateral ao tráfego, conforme figura 26.

Figura 26. Instalação dos gradis de aço sobre as barreiras New Jersey.

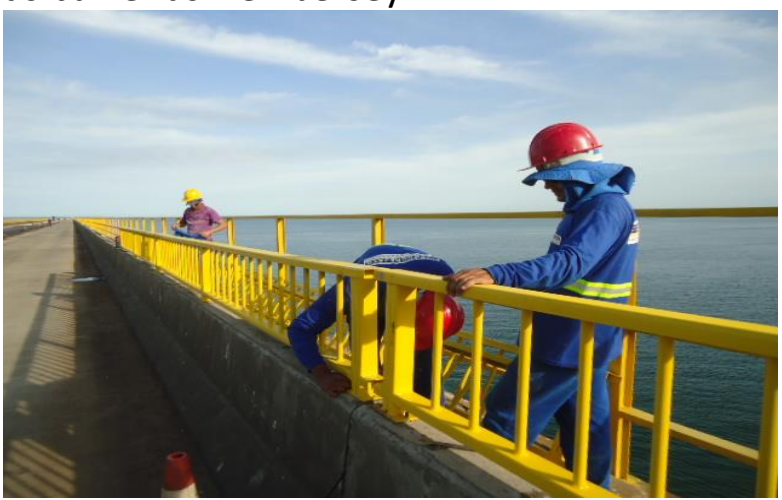

Fonte: O Autor (2012).

Ao longo de todo o processo de reabilitação do pavimento rígido, foram executados todos os controles tecnológicos 
previstos (figuras 27 e 28), além da execução dos serviços de recuperação do guarda-corpo original da ponte (figura 39). Ao final da obra também foram executados os serviços de limpeza da obra, sinalização horizontal e vertical da ponte e os furos no pavimento rígido de concreto e laje do tabuleiro, longitudinais às pistas de rolamento, com a função de drenagem das águas pluviais.

Figura 27. Moldagem dos corpos de prova no campo.

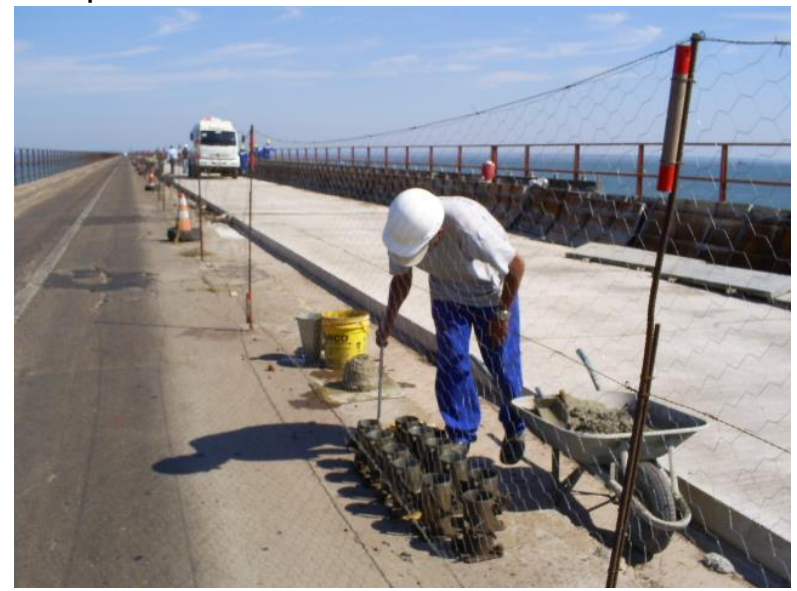

Fonte: O Autor (2012).

Figura 28. Execução de um dos ensaios de laboratório exigidos.

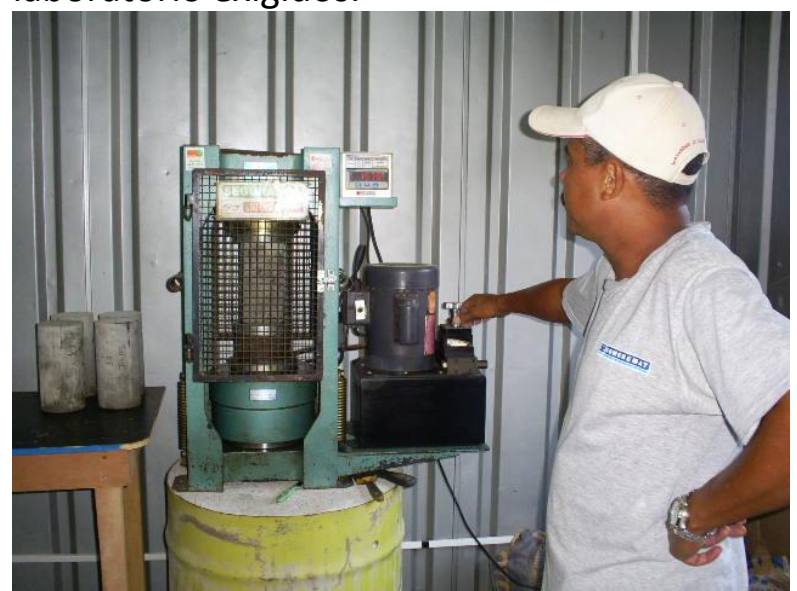

Fonte: O Autor (2012).
Figura 29. Execução do guarda-corpo original da ponte.

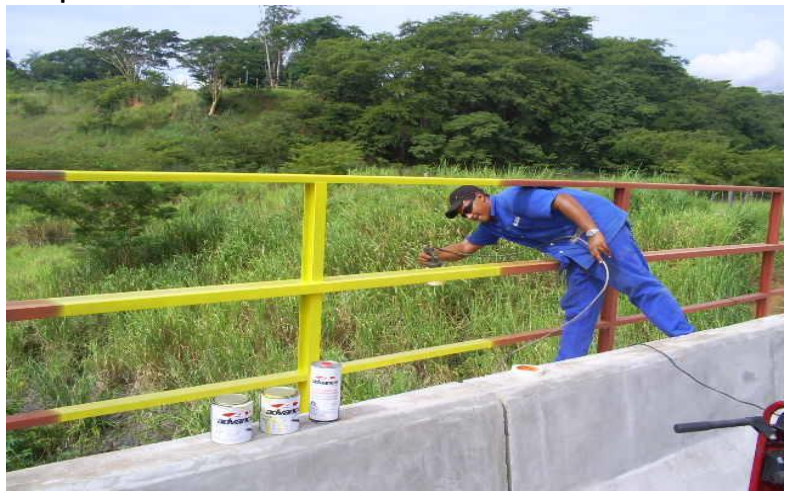

Fonte: O Autor (2012)

\section{CONCLUSÕES}

O manual de pavimentos rígidos do DNIT (2005) diz que os defeitos mais comuns nos pavimentos estão ligados ao uso inadequado de materiais e técnicas executivas, além da falta de manutenção adequada, sendo que esses fatores podem se agravar com o tempo. Com uma boa avaliação desses fatores, é possível obter parâmetros para programas de gerenciamento de pavimentos pelos entes governamentais responsáveis, estimando dessa forma a vida útil do pavimento, definição dos locais e épocas para execução de serviços de reparos, reforços ou reconstrução em função do acompanhamento da evolução dos problemas apresentados.

No caso do pavimento da ponte Maurício Joppert onde foi executada a recuperação total do pavimento rígido com a incorporação do mesmo ao tabuleiro, por motivos que não conhecemos, esses procedimentos não foram aplicados, pois como o ente público responsável demorou a agir de forma consistente na recuperação e manutenção do pavimento quando o mesmo começou a apresentar sinais de fadiga, qualquer tipo de ação que não fosse de grande porte, não teria mais função, pois os problemas iniciais foram se agravando e a única forma de saná-los definitivamente eram a execução das intervenções mostradas anteriormente.

Com as obras finalizadas, além do aumento da qualidade do pavimento, da 
segurança de trafegabilidade aos usuários e da rigidez da estrutura, devido à incorporação do pavimento à laje do tabuleiro, provavelmente haverá uma diminuição de acidentes no local, pois os usuários que trafegam pela ponte diariamente ou então, aqueles que passarão somente uma vez pelo local poderão sentir o extremo conforto e segurança ao dirigir, devido ao excelente nivelamento topográfico do novo pavimento e as sinalizações horizontais e verticais implantadas na ponte.

\section{REFERÊNCIAS}

MESQUITA, J.C.L. Pavimento rígido como alternativa econômica para pavimentação rodoviária. Estudo de caso - Rodovia BR-262, Miranda - Morro do Azeite - MS. Florianópolis: Universidade Federal de Santa Catarina, 2001.

SILVA, J.E.M.; CARNEIRO, L.A.V. Pavimentos de concreto: histórico, tipos e modelo de fadigas. Rio de Janeiro: Instituto militar de engenharia, 2014.

DER/SP - DEPARTAMENTO DE ESTRADAS E RODAGEM DO ESTADO DE SÃO PAULO. Manual de Normas - Pavimentação. Obra de arte. ET-DE-P00/047. São Paulo, 2007.

DER/SP - DEPARTAMENTO DE ESTRADAS E RODAGEM DO ESTADO DE SÃO PAULO. Manual de Normas - Pavimentação. Reabilitação. ET-DE-P00/046. São Paulo, 2007.

DNIT - DEPARTAMENTO NACIONAL DE INFRAESTRUTURA DE TRANSPORTES. Manual de pavimentos rígidos. 2. ed. Rio de Janeiro, 2005.

DNIT - DEPARTAMENTO NACIONAL DE INFRAESTRUTURA DE TRANSPORTES. Pavimento rígido - Avaliação objetiva Procedimento. DNIT 062/2004- PRO. Rio de Janeiro, 2004. 